\title{
ADSORPTION OF CATIONIC DYE FROM AQUEOUS SOLUTION USING COMPOSITE CHICKEN EGGSHELL - ANTHILL CLAY: OPTIMIZATION OF ADSORBENT PREPARATION CONDITIONS
}

\author{
ADEYINKA SIKIRU YUSUfF
}

\author{
Afe Babalola University, College of Engineering, Department of Chemical and Petroleum Engineering, \\ Ado-Ekiti, Nigeria \\ correspondence: yusuffas@abuad.edu.ng
}

\begin{abstract}
A composite adsorbent was prepared from anthill and eggshell mixture, using an incipient wetness impregnation method and it was used for an adsorption of cationic dye (methylene blue, MB) from an aqueous solution. The effects of three preparation parameters including calcination temperature, calcination time and mixing ratio of eggshell to anthill on the MB uptake were investigated using the central composite design (CCD) of response surface methodology (RSM). A quadratic model was developed to predict the response with a high accuracy. The optimal adsorbent sample was characterized by scanning electron microscopy (SEM), Fourier transform infrared (FTIR) spectroscopy and X-ray fluorescence $(\mathrm{XRF})$ spectroscopy. The obtained results revealed that the calcination temperature significantly affected the MB adsorption. The optimum MB uptake of $23.87 \mathrm{mg} / \mathrm{g}$ was achieved under the optimum conditions including a calcination temperature of $823.45{ }^{\circ} \mathrm{C}$, calcination time of $3.54 \mathrm{~h}$ and eggshell/anthill mixing ratio of 1.89:1. A detailed characterization of an optimal adsorbent sample confirmed the presence of pores, active functional groups and various molecular adsorption sites on its surface. Equilibrium adsorption isotherms and kinetics were also studied and it was revealed that the isotherms and kinetics data fitted well to the Freundlich model and pseudo-second-order kinetics model, respectively.
\end{abstract}

KEYWORDS: Anthill, adsorption, central composite design, eggshell, methylene blue.

\section{INTRODUCTION}

The generation of wastewater containing dye by textile industry has become an issue as its release into the environment usually leads to water pollution. Generally, these effluents contain a significant amount of basic dyes that are harmful to human beings and aquatic species. For example, they give colour to surface water, which alters the availability and toxicity of heavy metals to aquatic life [1]. In the last decade, most researchers are searching for appropriate treatments in order to remove these harmful pollutants and to achieve a complete degradation of effluent containing dyes [2]. In general, treatment of industrial effluents, which contain dyes, is being achieved by the Fentonbiological method, ultrafiltration, ion exchange membrane, chemical precipitation, electrochemical degradation, photocatalytic process and adsorption [3-8]. Among these treatment methods, adsorption process is found to be efficient, because most dyes are difficult to breakdown biologically, hence can easily be removed by porous solid material called adsorbent 1. Researches have proven that adsorbents, such as alumina, silica gel, commercial activated carbon and molecular sieves, are effective for the removal of dyes from wastewater [9, 10. However, these adsorbents are expensive, thus making the search for alternative adsorbents necessary. Such alternatives could be sourced from agricultural waste/biomass [11, 12, naturally occurring materials [13, microorganism [14] and industrial waste [15].

In the present study, the aim is to prepare a composite adsorbent from an anthill clay and chicken eggshells, optimize the preparation process condition and apply to methylene blue (MB) adsorption. The $\mathrm{MB}$ is chosen among the available dyes because of its visibility even in small quantity. An anthill is a form of clay, which is formed at the entrances of ant colonies [16. It has numerous industrial usefulness, including ceramic, cement, bricks, and sand casting making [17] and catalyst synthesis [18]. Chicken eggshells are agricultural waste, which poses a solid waste disposal menace. Eggs are commonly a consumable product worldwide because of its nutritional values [19. However, over $90 \%$ by weight of a dried eggshell is calcium carbonate $\left(\mathrm{CaCO}_{3}\right)$, and therefore, it is possible to synthesize calcium oxide $(\mathrm{CaO})$ based adsorbent from waste eggshells. Several researchers have synthesized $\mathrm{CaO}$ based adsorbents from different birds' eggshells for the removal of MB from an aqueous solution [20, 21]. Meanwhile, the adsorption site in an activated eggshell adsorbent had been determined to be only $\mathrm{CaO}[22]$, which might not be sufficient enough to completely remove the adsorbate. This is substantiated by Tsai et al. [20, who determined the adsorption capacity of an eggshell adsorbent for MB removal to be relatively low $(0.8 \mathrm{mg} / \mathrm{g})$. To the best of my knowledge, no study has been conducted on the 
optimization of preparation conditions of a composite adsorbent from eggshells and anthill clay for MB dye adsorption using the design of an experiment.

The use of a suitable statistical design of experiment in determining the influence of operational parameters is necessary. However, among the various optimization and statistical tools contained in design expert software, response surface methodology (RSM) has been regarded as the most powerful tool because it could identify and quantify interactions between variables [22]. It has been widely employed in numerous chemical engineering operations, such as catalysis, coagulation, photocatalytic degradation, adsorption and biodiesel synthesis [2, 9, 23, 24]. The application of statistical experimental design techniques in the development of the adsorption process can result in a reduced process variability coupled with the requirement of less resources (time, raw materials and experimental work) 10. Number of experimental runs required is dependent on the type of the design chosen: central composite design (CCD) or Box-Behnken designs [24, 25]. The difference between these two forms of the RSM design is the number of runs required and combinations of the levels [10. In the case of the CCD, almost as much information is provided as a multilevel factorial, which requires very few experiments compared to a full factorial. Therefore, in this present study, the central composite design (CCD) has been employed for the optimization of the preparation condition of a composite eggshell anthill clay (CEAC) adsorbent. The variables considered were calcination temperature, calcination time and mixing ratio of eggshell to anthill clay. Also, the optimal CEAC adsorbent sample was characterized by using various characterization techniques, such as scanning electron microscopy (SEM), Fourier transform infrared (FTIR) spectroscopy and X-ray florescence (XRF). In addition, adsorption isotherms and kinetics parameters were evaluated in order to understand the adsorption mechanisms of MB dye onto CEAC.

\section{MATERIAL AND METHODS}

\subsection{MATERIAL}

The chicken eggshells were collected from the cafeteria of postgraduate students, Afe Babalola University, (ABUAD), Ado-Ekiti, Nigeria. While the anthill situated behind Fidelity Bank, ABUAD, Ado-Ekiti, Nigeria was harvested. The cationic dye used as adsorbate was methylene blue (MB), which was collected from Department of Chemistry, ABUAD, AdoEkiti, Nigeria. MB's molecular formula and weight are $\mathrm{C}_{16} \mathrm{H}_{18} \mathrm{~N}_{3} \mathrm{CIS}$ and $319.85 \mathrm{~g} / \mathrm{mol}$ respectively. A $1000 \mathrm{mg} / \mathrm{L}$ stock solution of MB was prepared by dissolving $1.00 \mathrm{~g}$ of $\mathrm{MB}$ dye in $1000 \mathrm{~mL}$ of de-ionized water. Various solutions of needed initial MB concentrations $(25,50,100,150,200,250$ and $300 \mathrm{mg} / \mathrm{L})$ were obtained by diluting the stock solution with the required amount of de-ionized water.

\subsection{Preparation of composite EGGSHELL-ANTHILL CLAY (CEAC) ADSORBENT}

The waste eggshells were carefully washed to remove the white membrane and impurities from it and was, thereafter, heated up at $110^{\circ} \mathrm{C}$ in an oven overnight in order to remove residual moisture. The dried eggshells were ground with the aid of a mechanical grinder and then kept in a covered plastic container. The anthill was crushed into a powder, and thereafter kept in a covered plastic container. Both powders' particles were sieved to obtain a particle size of $125-300 \mu \mathrm{m}$. The screened eggshell and anthill powders were mixed in different proportions of anthill to eggshells according to the data points suggested by the central composite design (Table 1). An adequate amount of distilled water was added to the mixtures contained in a beaker to form a suspension and stirred for $2 \mathrm{~h}$ on a hot plate to achieve a homogenous mixture. The mixtures were then filtered and the residue was placed in an oven to remove any excess water at a temperature of $125^{\circ} \mathrm{C}$ for $2 \mathrm{~h}$. The twenty different proportions of dried mixed anthill-eggshell powders were thus calcined in a muffle furnace at a different temperature in a range between 700 and $900{ }^{\circ} \mathrm{C}$, and different corresponding time in a range between 1 and $4 \mathrm{~h}$ with a heating rate of $10^{\circ} \mathrm{C} / \mathrm{min}$.

\subsection{DESIGN OF EXPERIMENT}

In order to evaluate the effect of adsorbent preparation process parameters on the MB removal uptake, three main factors were considered: calcination temperature, $x_{1}{ }^{\circ} \mathrm{C}$, calcination time, $x_{2} \mathrm{~h}$ and mixing ratio of eggshells to anthill, $x_{3}$. A total of twenty experiments were conducted in this work, $2^{3}=8$ factorial points, 6 axial points and 6 replicates at the centre point. The experimental ranges and levels of the adsorbent preparation variables for the MB removal are given in Table 1. The extreme values of those variables considered were chosen based on results obtained from a preliminary experiment. The coded values were denoted by -1 (low level), 0 (center point), +1 (high level) and $\pm \alpha$ (distance from the centre point, which can be inside or outside the range).

The MB uptake, a response, was used to develop a mathematical model that correlates it to the adsorbent preparation process parameters by the second-order polynomial equation expressed in Eq. 1. However, the response was determined via an adsorption of $\mathrm{MB}$ onto prepared composite adsorbents.

$$
\begin{aligned}
Y=a_{0}+ & a_{1} x_{1}+a_{2} x_{2}+a_{3} x_{3}+a_{12} x_{1} x_{2}+a_{13} x_{1} x_{3}+ \\
& +a_{23} x_{2} x_{3}+a_{11} x_{1}^{2}+a_{22} x_{2}^{2}+a_{33} x_{3}^{2}
\end{aligned}
$$

\subsection{BATCH EQUILIBRIUM STUDIES}

Batch mode adsorption experiments were performed in twenty sets of $250 \mathrm{~mL}$ conical flasks in which $100 \mathrm{~mL}$ of the MB solution with an initial concentration of 


\begin{tabular}{clccccc}
\hline \multirow{2}{*}{ Variables } & \multirow{2}{*}{ Description } & \multicolumn{5}{c}{ Level } \\
\cline { 3 - 7 } & & $-\alpha$ & -1 & 0 & 1 & $+\alpha$ \\
\hline$x_{1}$ & Calcination temperature $\left({ }^{\circ} \mathrm{C}\right)$ & 668.4 & 700 & 800 & 900 & 931.6 \\
$x_{2}$ & Calcination time $(\mathrm{h})$ & 0.5 & 1 & 2.5 & 4 & 4.5 \\
$x_{3}$ & Mixing ratio of eggshell to anthill clay & 0.5 & 1 & 2.5 & 4 & 4.5 \\
\hline
\end{tabular}

TABLE 1. Levels of the composite adsorbent preparation variables chosen for this study.

$50 \mathrm{mg} / \mathrm{L}$ was charged into each flask and $0.2 \mathrm{~g}$ of each of the prepared composite adsorbent was also added to each flask. The flask and its contents were agitated in a thermostatic water bath shaker (SearchTech Instrument) operated at $30^{\circ} \mathrm{C}$ and $150 \mathrm{rpm}$ until an equilibrium was reached. The residual $\mathrm{MB}$ concentration was analysed on a double beam UV-vis spectrophotometer (UV- 1920 Jenway, UK) at a maximum absorbance wavelength of $660 \mathrm{~nm}$. The uptake of the MB was thus calculated by using Equation 2

$$
q_{e}=\frac{\left(C_{0}-C_{e}\right) V}{w}
$$

In order to evaluate the adsorption mechanisms of MB dye onto the composite adsorbent, batch adsorption experiments were further conducted at different concentrations of MB dye $(25-300 \mathrm{mg} / \mathrm{L})$ using an optimal composite eggshell-anthill clay (CEAC) sample as an adsorbent at the same operating parameters employed above. The un-adsorbed MB concentration was also analysed on the same double beam UV-vis spectrophotometer at a maximum absorbance wavelength of $660 \mathrm{~nm}$ and the MB dye adsorbed was also determined using the same eq. 2 .

\subsection{BATCH KINETIC EXPERIMENT}

The procedure employed in conducting the kinetic experiment was similar to that of the equilibrium study. The experiment was conducted by taking samples from the aqueous solutions at a pre-set time interval of every $10 \mathrm{~min}$ and the concentration of the residual MB dye concentrations were similarly determined. The kinetic experiment was carried out by considering the MB dye concentration of $50 \mathrm{mg} / \mathrm{L}$ using an optimal CEAC sample as an adsorbent at the same operating parameters employed in section 2.4. The dye uptake at a time $t, q_{t}$ was thus calculated as follows.

$$
q_{t}=\frac{\left(C_{0}-C_{t}\right) V}{w}
$$

\subsection{Characterization of the prepared COMPOSITE ADSORBENT}

The properties of the composite adsorbent prepared under optimum conditions was determined by using scanning electron microscopy (SEM), Fourier transform infrared (FTIR) spectroscopy and X-ray fluorescence (XRF) techniques. The SEM image of the optimal composite adsorbent was viewed through a microscope (SEM, JEOL-JSM 7600F) in order to examine its surface morphology, while the FTIR spectrophotometer (IR Affinity-1S, Shimadzu, Japan) was employed to determine the surface functional groups of the prepared adsorbent and the IR spectra of the sample studied were collected in the range of $4000-500 \mathrm{~cm}^{-1}$. The chemical composition of the asprepared CEAC adsorbent as well as the raw anthill and raw eggshell samples were determined by the XRF analysis.

\subsection{Adsorption isotherms}

The experimental results were analysed using twoparameter isotherm models (Langmuir and Freundlich isotherms). The essence of the adsorption isotherm is to correlate the bulk concentration of the MB dye to the equilibrium amount of the MB dye adsorbed at the interface [26]. The Langmuir model assumes a monolayer, homogenous adsorption site and thus, saturation is attained, beyond which no further attachment of the adsorbate on the adsorbent takes place. The nonlinear form of the Langmuir model is given by Eq. 4 .

$$
q_{e}=\frac{q_{\max } b C_{e}}{\left(1+b C_{e}\right)}
$$

Another important feature of the Langmuir isotherm model is the separation factor $\left(R_{L}\right)$, which determines the nature of the isotherm shape. It can either be favourable $\left(0<R_{L}<1\right)$, unfavourable adsorption $\left(R_{L}>1\right)$, linear $\left(R_{L}=1\right)$ or irreversible adsorption $\left(R_{L}=0\right)$. The dimensionless parameter is given by Eq. 5 .

$$
R_{L}=\frac{1}{\left(1+b C_{0}\right)}
$$

The Freundlich model assumes multilayer adsorption on heterogeneous surface and it is expressed in it nonlinear form as follows:

$$
q_{e}=k_{f} C_{e}^{1 / n}
$$

\subsection{Adsorption Kinetics}

In the present study, two different adsorption kinetic models, namely pseudo-first-order, and pseudo-secondorder were applied to evaluate the extent of the utilization of the adsorption capacity with respect to a contact time between the MB dye (adsorbate) and the CEAC (adsorbent). The linearized forms of the 
pseudo-first-order [27, and pseudo-second-order [28] models are expressed in Eqs. 7 and 8 respectively as follows:

$$
\begin{gathered}
\log \left(q_{e}-q_{t}\right)=\log \left(q_{e}\right)-\left(\frac{k_{1}}{2.303}\right) t \\
\frac{t}{q_{t}}=\frac{1}{k_{2} q_{e}^{2}}+\left(\frac{1}{q_{e}}\right) t
\end{gathered}
$$

\section{Results And Discussion}

\subsection{Central composite design (CCD) MODEL AND ANALYSIS}

The three-factor CCD matrix, as generated by the Design-Expert software (Trial version 7.0.0), and the experimental data obtained in the batch adsorption runs are presented in Table 2, According to the results obtained, an empirical model that correlates the dependent to independent variables was obtained and given by the Equation 9 Equation 9 represents the empirical model in terms of coded values.

$$
\begin{array}{r}
Y=24.43+2.04 x_{1}+0.86 x_{2}+0.95 x_{3}- \\
-2.21 x_{1} x_{2}-0.52 x_{1} x_{3}-0.25 x_{2} x_{3}- \\
-3.13 x_{1}^{2}-0.12 x_{2}^{2}-0.003 x_{3}^{2}
\end{array}
$$

The amounts of the MB adsorbed by various samples of the CEAC have been predicted by Eq. 2 and presented in Table 2 There was a cordial agreement between the predicted and experimental values of the MB uptake. The correlation between the actual and predicted responses was evaluated by a correlation coefficient $\left(R^{2}\right)$ and the value obtained $\left(R^{2}=0.9409\right)$ implies that the predicted values agreed excellently well with the experimental values. This indicates that only $94.09 \%$ of the total variations for the MB uptake are described by the model, while only about $5.91 \%$ of the variation is not explained by the model. The standard deviation was also used to measure the goodness of a fit. According to Tan et al. [9], the smaller the standard deviation is, the more accurate the dependent variable (response) is predicted by the model. The standard deviation for the developed model was found to be 1.07 and this indicates that the predicted values for the MB uptake matched the experimental values reasonably well.

The analysis of variance (ANOVA) is also a measure of the goodness of a fit. It is required to test the significance and adequency of the model [10]. ANOVA usually shows whether the variation from the developed model is significant or not when comapred with the one associated with the residual error 22. This comparison is done by $\mathrm{F}$-value, which is the ratio of the model mean square to the residual error. Accoding to Giwa et al. 10, the experimental result is said to be well predicted by the model, if the F-value obtained is greater that the tabualted value of the F-distribution. However, the F-value obtained herein is 17.69 indicating the adequency of the model fits. More so, $x_{1}, x_{2}, x_{3}, x_{1} x_{2}$, and $x_{1}^{2}$ are regarded as significant model terms, because their values of "prob $>F$ " are less than 0.05. Based on this result, the three independent variables studied had significant effects on the MB dye uptake. However, the calcination temperature $\left(x_{1}\right)$ had the most significant effect on the response due to its $\mathrm{F}$-value, which was discovered to be 41.71 (Table 3).

Fig. 1 shows the effect of the calcination temperature and calcination time on the MB dye uptake $(\mathrm{mg} / \mathrm{g})$ for the mixing ratio of eggshells to anthill clay of 2.5:1. As it can be seen from Fig. 1, the MB dye uptake increased with the increasing calcination temperature and calcination time. The reason for this observation is because both variables interact and were found to have synergistic effects on the adsorption capacity of the prepared composite adsorbent. As widely reported in literature, a high calcination temperature and calcination time enhanced pore creation and enlargement [9, 18. Thus, it indicates a good possibility for the adsorption of MB [9]. This phenomenon is further affirmed by the fact that the interaction of the calcination temperature with time has the most influential effect on the MB adsorbed as indicated by the highest F-value in the ANOVA (Table 3) compared to other interaction terms.

\subsection{Optimization of CEAC preparation PROCESS VARIABLES}

The optimum CEAC preparation conditions were established to be the calcination temperature of $823.45^{\circ} \mathrm{C}$, calcination time of $3.54 \mathrm{~h}$ and the mixing ratio of eggshells to anthill clay of 1.89 :1, which resulted in a $23.87 \mathrm{mg} / \mathrm{g}$ of MB uptake. However, the predicted MB dye uptake was calculated based on the empirical model developed by the design expert software and was found to be $24.93 \mathrm{mg} / \mathrm{g}$. Thus, the experimental value is in a good agreement with the predicted value with a relatively slight error between the two responses, which was only $4.44 \%$.

\subsection{Characterization of CEAC ADSORBENT PREPARED UNDER OPTIMUM CONDITIONS}

The SEM image shown in Fig. 2A revealed the surface morphology of the CEAC sample prepared under optimum conditions. It was observed that the surface of the adsorbent is rough, irregular and possesses pores of different sizes, which enhance the adsorption of the MB dye. After the adsorption of dyes, the morphology of the adsorbent changes and the pores initially present on its surface have been blocked by the dye molecules (Fig. 2B).

Fig. 3 shows the FTIR spectrum of the CEAC sample prepared under the optimum conditions. In the spectrum, a number of absorption bands are displayed indicating that several functional groups are present 


\begin{tabular}{cccccc}
\hline & \multicolumn{2}{c}{ Composite adsorbent preparation variables } & MB uptake, Y $(\mathrm{mg} / \mathrm{g})$ \\
\cline { 2 - 5 } Run No. & $\begin{array}{c}\text { Calcination } \\
\text { temperature }\end{array}$ & $\begin{array}{c}\text { Calcination } \\
\text { time }\end{array}$ & $\begin{array}{c}\text { Mixing proportion } \\
\text { of eggshell } \\
\text { to anthill }\end{array}$ & Predicted & Experimental \\
& $x_{1}\left({ }^{\circ} \mathrm{C}\right)$ & $x_{2}(\mathrm{~h})$ & $x_{3}$ & & \\
\hline 1 & $0(800)$ & $0(2.5)$ & $+\alpha(4.5)$ & 25.63 & 24.51 \\
2 & $+\alpha(931.6)$ & $0(2.5)$ & $0(2.5)$ & 21.69 & 21.71 \\
3 & $+1(900)$ & $-1(1)$ & $-1(1)$ & 23.85 & 23.72 \\
4 & $-\alpha(668.4)$ & $0(2.5)$ & $0(2.5)$ & 16.32 & 15.67 \\
5 & $-1(700)$ & $+1(4)$ & $+1(4)$ & 23.40 & 23.80 \\
6 & $0(800)$ & $0(2.5)$ & $-\alpha(0.5)$ & 23.12 & 23.61 \\
7 & $-1(700)$ & $-1(1)$ & $+1(4)$ & 17.76 & 18.37 \\
8 & $-1(700)$ & $+1(4)$ & $-1(1)$ & 20.95 & 21.97 \\
9 & $0(800)$ & $-\alpha(0.5)$ & $0(2.5)$ & 23.08 & 24.18 \\
10 & $+1(900)$ & $+1(4)$ & $+1(4)$ & 22.02 & 23.35 \\
11 & $+1(900)$ & $-1(1)$ & $+1(4)$ & 25.21 & 24.46 \\
12 & $0(800)$ & $+\alpha(4.5)$ & $0(2.5)$ & 25.35 & 23.62 \\
13 & $-1(700)$ & $-1(1)$ & $-1(1)$ & 14.31 & 13.25 \\
14 & $+1(900)$ & $+1(4)$ & $-1(1)$ & 21.67 & 21.33 \\
15 & $0(800)$ & $0(2.5)$ & $0(2.5)$ & 24.43 & 24.38 \\
16 & $0(800)$ & $0(2.5)$ & $0(2.5)$ & 24.43 & 24.48 \\
17 & $0(800)$ & $0(2.5)$ & $0(2.5)$ & 24.43 & 24.65 \\
18 & $0(800)$ & $0(2.5)$ & $0(2.5)$ & 24.43 & 24.60 \\
19 & $0(800)$ & $0(2.5)$ & $0(2.5)$ & 24.43 & 24.76 \\
20 & $0(800)$ & $0(2.5)$ & $0(2.5)$ & 24.43 & 24.49 \\
$0.9409 ;$ & $A d j-R^{2}=0.8877 \quad s t . d e v$ & 1.07 & & \\
\hline$R^{2}=$ & & & & \\
\hline
\end{tabular}

TABLE 2. Experimental design matrix and responses.

\begin{tabular}{lrrrrr}
\hline Source & Sum of squares & Degree of freedom & Mean square & F-value & Prob $>$ F \\
\hline Model & 182.68 & 9 & 20.30 & 17.69 & $<0.0001$ \\
$x_{1}$ & 47.84 & 1 & 47.84 & 41.71 & $<0.0001$ \\
$x_{2}$ & 8.57 & 1 & 8.57 & 7.47 & 0.0211 \\
$x_{3}$ & 10.35 & 1 & 10.35 & 9.03 & 0.0132 \\
$x_{1} x_{2}$ & 38.94 & 1 & 38.94 & 33.95 & 0.0002 \\
$x_{1} x_{3}$ & 2.19 & 1 & 2.19 & 1.91 & 0.1967 \\
$x_{2} x_{3}$ & 0.51 & 1 & 0.51 & 0.44 & 0.5220 \\
$x_{1}^{2}$ & 68.27 & 1 & 68.27 & 59.51 & $<0.0001$ \\
$x_{2}^{2}$ & 0.10 & 1 & 0.10 & 0.091 & 0.7696 \\
$x_{3}^{2}$ & 6.17 & 1 & $6.17 \cdot 10^{-3}$ & $5.379 \cdot 10^{-3}$ & 0.9430 \\
Residual & 11.47 & 10 & 1.15 & - & - \\
\hline
\end{tabular}

TABLE 3. Analysis of variance (ANOVA) for response surface quadratic model for MB dye adsorption. 


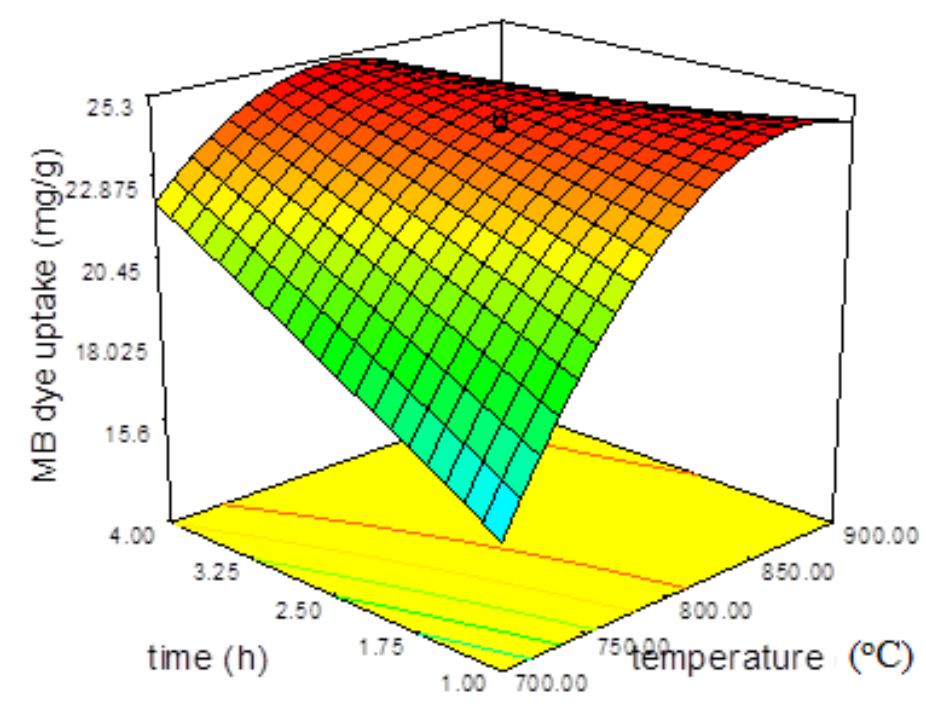

FIGURE 1. The response surface plot of MB uptake $(\mathrm{mg} / \mathrm{g})$ as the function of calcination temperature and calcination time at fixed 2.5:1 mixing ratio of eggshell to anthill clay.
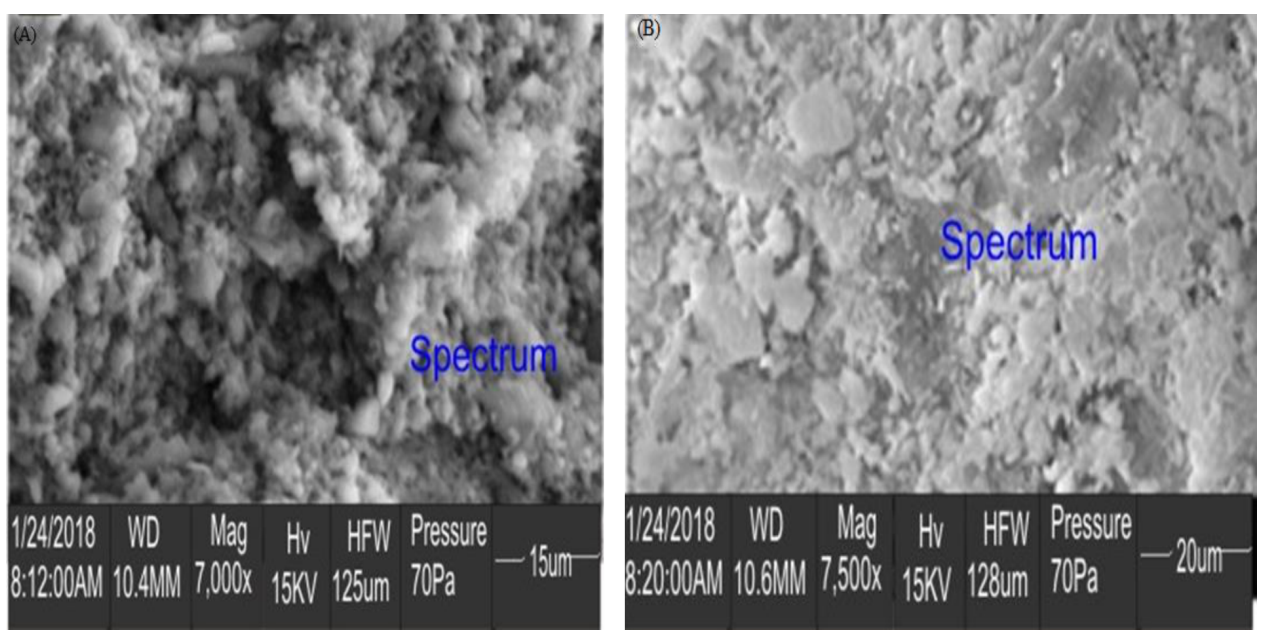

FigURE 2. SEM images of CEAC adsorbent (A) before adsorption and (B) after adsorption.

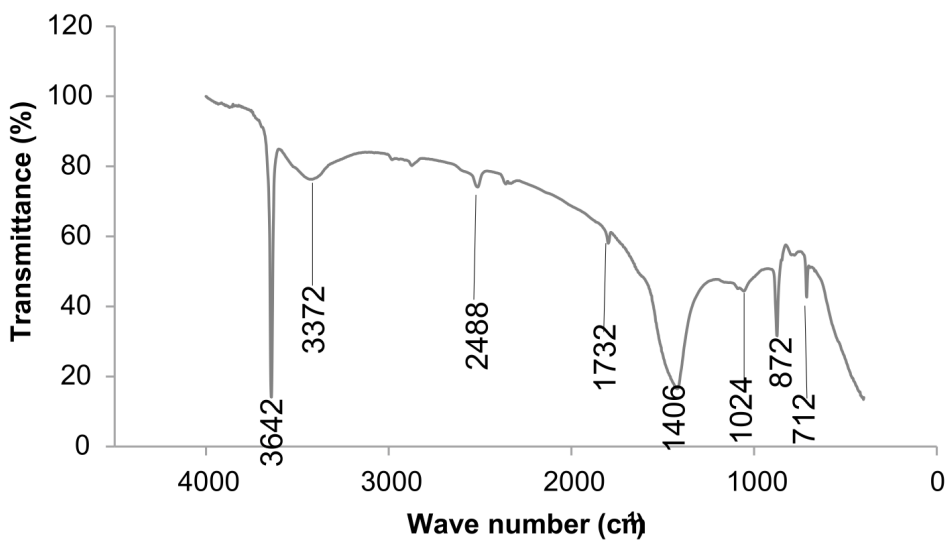

FIGURE 3. FTIR spectrum of CEAC adsorbent prepared under optimum conditions. 
on the adsorbent surface. The sharp and broad absorption bands at $3642 \mathrm{~cm}^{-1}$ and $3372 \mathrm{~cm}^{-1}$ respectively are assignable to a hydroxyl bond from the adsorbed moisture. The absorption bands observed at $2488 \mathrm{~cm}^{-1}$ and $1732 \mathrm{~cm}^{-1}$ are attributed to $\mathrm{S}-\mathrm{H}$ stretching and $\mathrm{C}=\mathrm{O}$ stretching respectively. While the band at $1024 \mathrm{~cm}^{-1}$ is due to the $\mathrm{P}-\mathrm{O}-\mathrm{C}$ antisymmetric stretching. The optimal CEAC adsorbent also shows another set of bands at $1406 \mathrm{~cm}^{-1}, 872 \mathrm{~cm}^{-1}$ and $712 \mathrm{~cm}^{-1}$ which can be respectively attributed to the in-plane-OH bending, the $\mathrm{CH}$ out-of-plane deformation and $\mathrm{OH}$ out-of-plane deformation. The high adsorption capacity of the optimal CEAC in the adsorption of dye from an aqueous solution may be due to the presence of the surface functional groups, among which carboxylic $(\mathrm{C}-\mathrm{O}$ and $\mathrm{C}=\mathrm{O})$ and hydroxyl $(\mathrm{OH})$ groups play the main role.

Table 4 depicts the chemical compositions of a raw anthill, raw eggshell and optimal CEAC adsorbent, which were determined by the XRF analysis. The major composition in the anthill sample were determined to be silica $\left(\mathrm{SiO}_{2}\right)$, alumina $\left(\mathrm{Al}_{2} \mathrm{O}_{3}\right)$ and zirconia $\left(\mathrm{ZrO}_{2}\right)$, while the main mineral composition in eggshells was found to be calcium oxide $(\mathrm{CaO})$. The high LOI in the raw anthill and eggshell samples is due to the presence of organic matters and moisture content 20]. However, $\mathrm{CaO}$ constitutes the larger amount in an optimal CEAC sample, followed by $\mathrm{SiO}_{2}$. It was observed that the calcination at $823.45^{\circ} \mathrm{C}$ for $3.54 \mathrm{~h}$ was able to transform the mixed eggshell-anthill clay into a synergetic mixed oxide structure. Thus, the result obtained indicates that not only $\mathrm{CaO}$ plays a significant role in the CEAC performance but also the other metal oxides $\left(\mathrm{SiO}_{2}, \mathrm{Al}_{2} \mathrm{O}_{3}, \mathrm{ZrO}_{2}\right.$ and $\left.\mathrm{Fe}_{2} \mathrm{O}_{3}\right)$ contained in the optimal CEAC sample can determine the form of the molecular adsorption sites and their level of capacity. The presence of $\mathrm{SiO}_{2}$ in the composite adsorbent plays a key role in the adsorption [29]. $\mathrm{SiO}_{2}$ is known as an inorganic adsorbent and could adsorb either positive or negative contaminant depending on the $\mathrm{pH}$ of the solution [30. Its surface contains silinol (OH group), which can act as the centre of a molecular adsorption during their specific interaction with adsorbates 31. Other mineral oxides, such as $\mathrm{Al}_{2} \mathrm{O}_{3}, \mathrm{Fe}_{2} \mathrm{O}_{3}$ and $\mathrm{ZrO}_{2}$, also exhibit the phenomenon of electrostatic interaction $30,32,33$. This indicates that the maximum dye adsorption capacity of the CEAC can be attributed to the electrostatic interaction of the adsorbate with the surface $\mathrm{CaO}$, $\mathrm{SiO}_{2}, \mathrm{Al}_{2} \mathrm{O}_{3}, \mathrm{ZrO}_{2}$ sites. This observation could be the reason why the CEAC adsorbent had an improved performance in the adsorption of the MB dye compared to the adsorbent prepared only from eggshells, which has a single adsorption site $(\mathrm{CaO})$.

\subsection{Adsorption isotherm}

The nonlinear plots of Langmuir and Freundlich models, amount of the MB dye adsorbed per unit mass of $\mathrm{CEAC}, q_{e}(\mathrm{mg} / \mathrm{g})$ versus equilibrium concentration
$\left(C_{e}\right)$ at fixed temperature of $30^{\circ} \mathrm{C}$ are depicted in Fig. 4. The values of parameters contained in Langmuir $\left(q_{\max }\right.$ and $\left.b\right)$ and Freundlich $\left(k_{F}\right.$ and $\left.n\right)$ models were all determined from the plots and are presented in Table 5 with their correlation coefficients $\left(R^{2}\right)$. The best model was selected based on the $R^{2}$ value and it was found out that Freundlich model provided the best fit with the experimental data. This indicates that the CEAC adsorbent surface is dominated by the multilayer and heterogeneous active sites. The value of $R_{L}(0.2717)$, as indicated in Table 5 , is less than 1 , which suggests a favourable adsorption process. This is confirmed by the magnitude of the Freundlich exponent $n$ (3.24) which also indicates a favourable adsorption condition, because $\mathrm{n}$ is greater than 1 .

A comparison of the adsorption capacities of the $\mathrm{CEAC}$ and other various adsorbents for the MB uptake from an aqueous environment are presented in Table 6. The CEAC is found to possess a relatively large adsorption capacity of $43.46 \mathrm{mg} / \mathrm{g}$ and this implies that the adsorbent is highly effective for the treatment of water and wastewater containing dye. It can be concluded that the value of $q_{\max }$ agrees excellently well with those reported by the previous researchers 28, 39, indicating that the MB dye could be effectively adsorbed on the CEAC synthesized in this work. In addition, the aim to investigate the performance of the CEAC in the adsorption of the MB from aqueous solution was successful as the uptake capacity of the CEAC $(43.46 \mathrm{mg} / \mathrm{g})$ is far greater than the value $(0.8 \mathrm{mg} / \mathrm{g})$ reported for the eggshells by Tsai et al. [20]. This result indicates that the anthill clay played a significant role in improving the adsorption properties of the prepared adsorbent.

\subsection{Adsorption KINETICS}

The kinetics parameters for the MB dye adsorption by the CEAC were determined from the combined plots of $\log \left(q_{e}-q_{t}\right)$ against $t$ (pseudo-first-order kinetics) and $t / q_{t}$ against $t$ (pseudo-second-order kinetics) shown in Fig. 5 . The magnitudes of the kinetics parameters are presented in Table 7 The results reveal that the calculated $q_{e}$ (cal) value does not match with experimental $q_{e}(\exp )$ value at an adsorbate concentration of $50 \mathrm{mg} / \mathrm{L}$ with low $R^{2}$ value (0.9861). Therefore, the adsorption of the MB dye onto the CEAC cannot be best predicted by a pseudo-firstorder kinetics model. However, the high $R^{2}$ value (0.9989) and cordial agreement between the calculated and experimental $q_{e}$ values of pseudo-second-order kinetics model compared to the pseudo-first-order kinetics as can be seen in Table 7 indicate that MB dye adsorption onto CEAC can be well predicted by the pseudo-second-order kinetics model.

\section{Conclusion}

The process conditions for the preparation of the CEAC adsorbent developed for the MB adsorption from an aqueous solution were optimized. The effect 


\begin{tabular}{lrrr}
\hline & \multicolumn{3}{c}{ Chemical composition } \\
\cline { 2 - 4 } Compound & Raw anthill & Raw eggshell & Optimal CEAC \\
\hline $\mathrm{SiO}_{2}$ & 63.51 & 0.79 & 9.83 \\
$\mathrm{Al}_{2} \mathrm{O}_{3}$ & 16.21 & 0.12 & 2.62 \\
$\mathrm{Fe}_{2} \mathrm{O}_{3}$ & 4.33 & 2.68 & 1.52 \\
$\mathrm{ZrO}_{2}$ & 6.83 & - & 1.15 \\
$\mathrm{MgO}$ & - & 1.78 & 0.14 \\
$\mathrm{CaO}$ & 1.22 & 86.74 & 81.57 \\
$\mathrm{~K}_{2} \mathrm{O}$ & 2.11 & 0.09 & 0.73 \\
$\mathrm{P}_{2} \mathrm{O}_{5}$ & - & 1.21 & 0.58 \\
$\mathrm{TiO}_{2}$ & 1.08 & - & - \\
$\mathrm{SO}_{3}$ & 0.02 & 0.12 & 0.08 \\
$\mathrm{LOI}$ & 4.69 & 6.47 & 1.78 \\
\hline
\end{tabular}

TABLE 4. Chemical composition analysis of raw anthill, raw eggshell and optimal CEAC adsorbent.

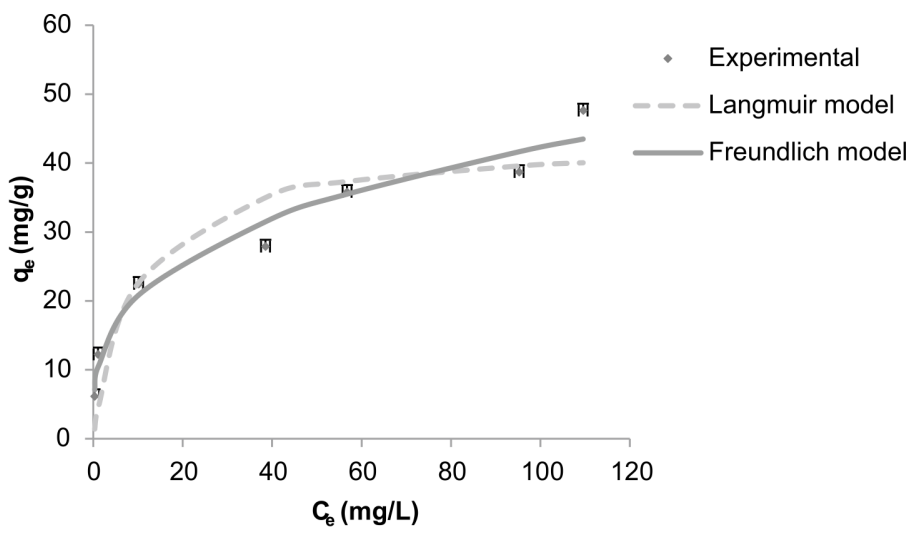

Figure 4. Two-parameter isotherm models for adsorption of $\mathrm{MB}$ dye onto CEAC at $30^{\circ} \mathrm{C}$.

\begin{tabular}{lr}
\hline Isotherm & Value \\
\hline Langmuir & \\
$q_{\max }(\mathrm{mg} / \mathrm{g})$ & 43.46 \\
$b(\mathrm{~L} / \mathrm{mg})$ & 0.1072 \\
$R^{2}$ & 0.9068 \\
$R_{L}$ & 0.2717 \\
& \\
Freundlich & \\
$k_{F}\left(\mathrm{mg} / \mathrm{g}(\mathrm{L} / \mathrm{mg})^{1 / n}\right)$ & 10.19 \\
$n$ & 3.24 \\
$R^{2}$ & 0.9652 \\
\hline
\end{tabular}

TABLE 5. Two-parameter isotherm constants and correlation coefficients for adsorption of MB dye on CEAC.

of operating parameters on the adsorption of the MB was evaluated by the central composite design. The optimum values of the calcination temperature, calcination time and mixing ratio of eggshells to anthill clay, $823.45^{\circ} \mathrm{C}, 3.54 \mathrm{~h}$ and $1.89: 1$ respectively, resulted in a $23.87 \mathrm{mg} / \mathrm{g}$ of the MB uptake. A high correlation coefficient $\left(R^{2}=0.9409\right)$ exhibited by an analysis of variance indicated a satisfactory adjustment of the

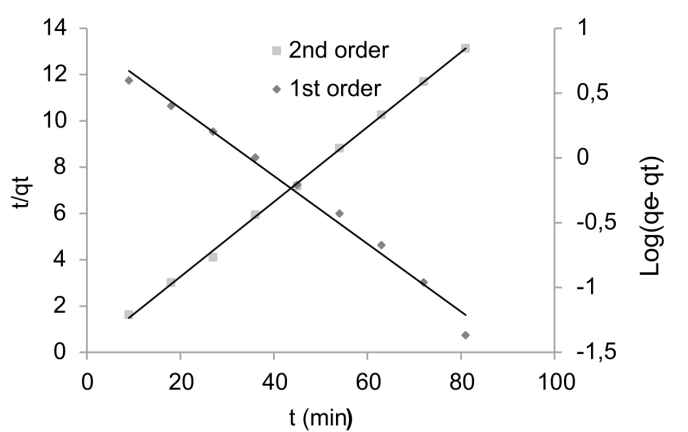

Figure 5. Pseudo-first-order and Pseudo-secondorder kinetics for adsorption of MB dye onto CEAC.

model developed with the experimental data. The result of the equilibrium adsorption isotherm analysis revealed that the isotherm data fitted well to the Freundlich model. The kinetic data analysis showed that the pseudo-second-order model provided the best fit with the experimental data suggesting a chemisorption process. 


\begin{tabular}{lccr}
\hline Adsorbent & $\begin{array}{c}\text { Maximum } \\
\text { adsorption } \\
\text { capacity } \\
(\mathrm{mg} / \mathrm{g})\end{array}$ & $\begin{array}{c}\text { Operating } \\
\text { temperature }\end{array}$ & Reference \\
\hline Eggshell & 0.80 & 25 & {$[20]$} \\
Eggshell membrane & 0.24 & 25 & {$[20]$} \\
Acrylic polymer/bentonite composite & 36.60 & $30-70$ & {$[33]$} \\
Crushed brick & 96.61 & 20 & {$[34]$} \\
Rice husk & 40.58 & 25 & {$[35]$} \\
Wheat shells & 16.56 & 30 & {$[36]$} \\
Orange peel & 18.60 & 30 & {$[38]$} \\
Raw orange tree sawdust & 39.68 & 20 & Present study \\
Alkali-treated orange tree sawdust & 78.74 & 20 & 30 \\
CEAC & 43.46 & & {$[36$} \\
\hline
\end{tabular}

TABLE 6. Comparison of monolayer adsorption capacities of different adsorbents for MB dye adsorption.

\begin{tabular}{lc}
\hline Kinetic model & Value of parameter \\
\hline Pseudo-first-order & \\
$q_{e}(\exp )(\mathrm{mg} / \mathrm{g})$ & 6.1720 \\
$q_{e}(\mathrm{cal})(\mathrm{mg} / \mathrm{g})$ & 2.4773 \\
$k_{1}\left(\mathrm{~min}^{-1}\right)$ & 0.0603 \\
$R^{2}$ & 0.9861 \\
& \\
Pseudo-second-order & \\
$q_{e}(\mathrm{cal})(\mathrm{mg} / \mathrm{g})$ & 6.1805 \\
$k_{2}\left(\mathrm{gmg}^{-1} \mathrm{~min}^{-1}\right)$ & 0.8555 \\
$R^{2}$ & 0.9989 \\
\hline
\end{tabular}

TABLE 7. Kinetic parameters of MB dye adsorption on CEAC.

\section{LIST OF SYMBOLS}

$Y$ response variable of $\mathrm{MB}$ uptake $[\mathrm{mg} / \mathrm{g}]$

$x_{1}$ calcination temperature $\left[{ }^{\circ} \mathrm{C}\right]$

$x_{2}$ calcination time $[\mathrm{h}]$

$x_{3}$ mixing ratio of eggshells to anthill clay

$a_{i s}$ regression coefficients for linear terms

$a_{i k}$ regression coefficients for quadratic terms

$C_{o}$ initial concentration of MB dye in aqueous solution $[\mathrm{mg} / \mathrm{L}]$

$C_{e}$ equilibrium concentration of $\mathrm{MB}$ dye in aqueous solution $[\mathrm{mg} / \mathrm{L}]$

$C_{t}$ liquid-phase concentration of $\mathrm{MB}$ at time $\mathrm{t}[\mathrm{mg} / \mathrm{L}]$

$V$ volume of the MB dye solution [L]

$w$ weight of adsorbent used [g]

$q_{e}$ amount of MB dye adsorbed at equilibrium [mg/g]

$q_{\max }$ maximum adsorption capacity $[\mathrm{mg} / \mathrm{g}]$

$b \quad$ Langmuir equilibrium constant $[\mathrm{L} / \mathrm{mg}]$

$R_{L}$ Separation factor

$k_{F} \quad$ Freundlich equilibrium constant $\left[\mathrm{mg} / \mathrm{g}(\mathrm{L} / \mathrm{mg})^{1 / n}\right]$

$n$ adsorption intensity

$q_{t}$ amount of MB dye adsorbed at time $\mathrm{t}[\mathrm{mg} / \mathrm{g}]$

$k_{1}$ pseudo-first-order rate constant $[1 / \mathrm{min}]$

$k_{2}$ pseudo-second-order rate constant [g/(mg min $\left.)\right]$

\section{REFERENCES}

[1] S. Markandeya, P. Shukla, D. Mohan. Toxicity of disperse dyes and its removal from wastewater using various adsorbents: A review. Research Journal of Environmental Toxicology 11:72-89, 2017.

[2] A. Giwa, P. Nkeonye, K. Bello, E. Kolawole. Solar photocatalytic degradation of acid blue 29. Journal of the Chemical Society of Nigeria 36(1):82-89, 2011.

[3] Y. Bulut, H. Aydın. A kinetics and thermodynamics study of methylene blue adsorption on wheat shells. Desalination 194:259-267, 2006. DOI:10.1016/j.desal.2005.10.032.

[4] T. Lakdioui, A. Essamri, A. El Harfi. Optimization study of ultrafiltration rate of a membrane based on polysulfone modified titanium dioxide on coloured water by indigo. Journal of Materials and Environmental Sciences 8(11):4052-4056, 2017.

[5] Y. O. Khaniabadi, M. J. Mohammadi, M. Shegerd, et al. Removal of Congo red dye from aqueous solutions by a low-cost adsorbent: activated carbon prepared from Aloe vera leaves shell. Environmental Health Engineering And Management Journal 4(1):29-35, 2017.

[6] S. Alahiane, A. Sennaoui, F. Safr, et al. A study of the photocatalytic degradation of the textile dye Reactive Yellow 17 in aqueous solution by TiO2-coated non-woven fibres in a batch photoreactor. Journal of Materials and Environmental Science 8(10):3556-3563, 2017.

[7] M. S. Morsi, A. A. Al-Sarawy, W. A. Shebab El-Dein. Electrochemical degradation of some organic dyes by electrochemical oxidation on a $\mathrm{Pb} / \mathrm{PbO} 2$ electrode. Desalination and Water Treatment 26:301-308, 2011. DOI:10.5004/dwt.2011.1926.

[8] A. Aru, M. Saravanan. Adsorption of congo red dye from aqueous solution onto a low-cost natural orange peel and groundnut shell powder. Der Pharmacia Lettre 7:332-337, 2015.

[9] I. A. W. Tan, A. L. Ahmad, B. Hameed. Preparation of activated carbon from coconut husk: Optimization study on removal of 2,4,6-trichlorophenol using response surface methodology. Journal of hazardous materials 153:709-717, 2008. DOI:10.1016/j.jhazmat.2007.09.014. 
[10] A. Giwa, U. G. Akpan, B. H. Hameed. Optimization of photocatalytic degradation of an anthraquinone dye using design of experiment. Journal of Engineering Research 17(3):20-31, 2012.

[11] A. S. Yusuff, I. I. Olateju. Experimental investigation of adsorption capacity of anthill in the removal of heavy metals from aqueous solution. Environmental Quality Management 27(3):53-59, 2018. DOI:10.1002/tqem.21536

[12] A. A. Azzaz, S. Jellali, H. Akrout, et al. Dynamic investigations on cationic dye desorption from chemically modified lignocellulosic material using a low-cost eluent: Dye recovery and anodic oxidation efficiencies of the desorbed solutions. Journal of cleaner production 201:28-38, 2018. DOI:10.1016/j.jclepro.2018.08.023

[13] Z. Mohamed, A. Abdelkarim, K. Ziat, S. Mohamed. Adsorption of $\mathrm{Cu}$ (II) onto natural clay: Equilibrium and thermodynamic studies. Journal of Materials and Environmental Sciences 7:566-570, 2016.

[14] M. J. Mohammed-Ridha, A. S. Ahmed, N. N. Raoof. Investigation of the thermodynamic, kinetic and equilibrium parameters of batch biosorption of $\mathrm{Pb}$ (II), $\mathrm{Cu}$ (II), and Ni (II) from aqueous phase using low cost biosorbent. Al-Nahrain Journal for Engineering Sciences 20(1):298-310, 2017.

[15] F. Gorzin, M. M. Bahri Rasht Abadi. Adsorption of Cr (VI) from aqueous solution by adsorbent prepared from paper mill sludge: Kinetics and thermodynamics studies. Adsorption Science and Technology 36(1-2):149-169, 2018. DOI:10.1177/0263617416686976

[16] G. A. Henne. Anthill as a resource for ceramics. Ph.D. thesis, Faculty of fine art, Kwame Nkrumah University of Science and Technology, 2009.

[17] A. D. Akinwekomi, J. A. Omotoyinbo, D. Folorunso. Effect of high alumina cement on selected foundry properties of anthill clay. Leonardo Electronic Journal of Practices and Technology 1:37-46, 2012.

[18] A. Yusuff, O. Adeniyi, M. Olutoye, U. G. Akpan. Development and characterization of a composite anthillchicken eggshell catalyst for biodiesel production from waste frying oil. International Journal of Technology 9:110-119, 2018. DOI:10.14716/ijtech.v9i1.1166

[19] Y. C. Sharma, B. Singh, J. Korstad. Application of an efficient nonconventional heterogeneous catalyst for biodiesel synthesis from Pongamia pinnata oil. Energy and Fuels 24:3223-3231, 2010. DOI:10.1021/ef901514a.

[20] W. T. Tsai, J.-m. Yang, C. W. Lai, et al. Characterization and adsorption properties of eggshells and eggshell membrane. Bioresource technology 97:488-493, 2006. DOI:10.1016/j.biortech.2005.02.050.

[21] M. Elkady, A. Ibrahim, M. Abd El-Latif. Assessment of the adsorption kinetics, equilibrium and thermodynamic for the potential removal of reactive red dye using eggshell biocomposite beads. Desalination 278:412-423, 2011. DOI:10.1016/j.desal.2011.05.063.

[22] M. Zarei, A. Niaei, D. Salari, A. Khataee. Application of response surface methodology for optimization of peroxi-coagulation of textile dye solution using carbon nanotube-PTFE cathode. Journal of hazardous materials 173:544-551, 2010. DOI:10.1016/j.jhazmat.2009.08.120.
[23] M. Olutoye, O. Adeniyi, A. Yusuff. Synthesis of biodiesel from palm kernel oil using mixed clay-eggshell heterogeneous catalysts. Iranica Journal of Energy and Environment 7(3):308-314, 2016. DOI:10.5829/idosi.ijee.2016.07.03.14

[24] D. Montgomery. Design and analysis of experiment. John Wiley and Sons, New York, USA, 2005.

[25] D. M. R.H. Myer. Response Surface Methodology: Process and Product Optimization Using Designed Experiments. John Wiley and Sons, New York, USA, 2nd edn., 2002.

[26] B. Hameed, R. R. Krishni, S. Sata. A novel agricultural waste adsorbent for the removal of cationic dye from aqueous solutions. Journal of hazardous materials 162:305-11, 2009. DOI:10.1016/j.jhazmat.2008.05.036

[27] S. Langergren. About the theory of so-called adsorption of soluble subtances. Kungliga Svenska Vetenskapsakademiens Handlingar 24(4):1-39, 1898.

[28] Y.-S. Ho, G. Mckay. Kinetic models for the sorption of dye from aqueous solution by wood. Process Safety and Environmental Protection 76:183-191, 1998. DOI:10.1205/095758298529326

[29] A. Fisli, Y. Krisnanandi, J. Gunlazuardi. Preparation and characterization of $\mathrm{Fe} 2 \mathrm{O} 3 / \mathrm{SiO} 2 / \mathrm{TiO} 2$ composite for methylene blue removal in water. International Journal of Technology 1:76-84, 2017.

[30] M. Mohapatra, S. Khatun, S. Anand. Adsorption behaviour of $\mathrm{Pb}(\mathrm{II}), \mathrm{Cd}(\mathrm{II})$ and $\mathrm{Zn}(\mathrm{II})$ on NALCO plant sand. Indian Journal of Chemical Technology 16:291-300, 2009.

[31] L. Zhuravlev. The surface chemistry of amorphous silica. Zhuravlev model. Colloids and Surfaces A: Physicochemical and Engineering Aspects 173:1-38, 2000. DOI:10.1016/S0927-7757(00)00556-2

[32] A. Yusuff, A. Gbadamosi, M. Lala, J. F. Ngochindo. Synthesis and characterization of anthill-eggshell composite adsorbent for removal of hexavalent chromium from aqueous solution. Environmental Science and Pollution Research 25(19):19143-19154, 2018. DOI:10.1007/s11356-018-2075-2

[33] S. Farhan Azha, S. Abd Hamid, S. Ismail. Development of composite adsorbent coating based acrylic polymer/bentonite for methylene blue removal. Journal of Engineering and Technological Sciences 49(02):225-235, 2017. DOI:10.5614/j.eng.technol.sci.2017.49.2.5

[34] B. Noroozi, G. Sorial, H. Bahrami, M. Arami. Equilibrium and kinetic adsorption study of a cationic dye by a natural adsorbent - silkworm pupa. Journal of hazardous materials 139:167-74, 2007. DOI:10.1016/j.jhazmat.2006.06.021

[35] V. Vadivelan, K. V. Kumar. Equilibrium, kinetics, mechanism, and process design for the sorption of methylene blue onto rice husk. Journal of Colloid and Interface Science 286:90-100, 2005. DOI:10.1016/j.jcis.2005.01.007.

[36] Y. Bulut, H. Aydın. A kinetics and thermodynamics study of methylene blue adsorption on wheat shells. Desalination 194:259-267, 2006. DOI:10.1016/j.desal.2005.10.032 
[37] G. Annadurai, R.-S. Juang, D.-J. Lee. Use of cellulose-based wastes for adsorption of dyes from aqueous solutions. Journal of Hazardous Materials 92:263-274, 2002. DOI:10.1016/S0304-3894(02)00017-1

[38] A. A. Azzaz, S. Jellali, H. Akrout, et al.

Optimization of a cationic dye removal by a chemically modified agriculture by-product using response surface methodology: biomasses characterization and adsorption properties. Environmental Science and Pollution Research 24(11):9831-9846, 2017. DOI:10.1007/s11356-016-7698-6.
[39] M. C. Ncibi, B. Mahjoub, M. Seffen. Kinetic and equilibrium studies of methylene blue biosorption by Posidonia oceanica (L.) fibres. Journal of hazardous materials 139:280-285, 2007.

DOI:10.1016/j.jhazmat.2006.06.029 